NBER WORKING PAPER SERIES

\title{
AN INTENSIVE EXPLORATION OF TECHNOLOGY DIFFUSION
}

\author{
Diego A. Comin \\ Martí Mestieri \\ Working Paper 16379 \\ http://www.nber.org/papers/w16379
}

\author{
NATIONAL BUREAU OF ECONOMIC RESEARCH \\ 1050 Massachusetts Avenue \\ Cambridge, MA 02138 \\ September 2010
}

We would like to thank Mar Reguant for comments and suggestions. Comin would like to thank the NSF (Grants \# SES-0517910 and SBE-738101) for their financial assistance. The views expressed in this paper solely reflect those of the authors and not necessarily those of the National Bureau of Economic Research.

NBER working papers are circulated for discussion and comment purposes. They have not been peerreviewed or been subject to the review by the NBER Board of Directors that accompanies official NBER publications.

(C) 2010 by Diego A. Comin and Martí Mestieri. All rights reserved. Short sections of text, not to exceed two paragraphs, may be quoted without explicit permission provided that full credit, including $\odot$ notice, is given to the source. 
An Intensive Exploration of Technology Diffusion

Diego A. Comin and Martí Mestieri

NBER Working Paper No. 16379

September 2010

JEL No. E13,O14,O33,O41

\begin{abstract}
$\underline{\text { ABSTRACT }}$
We present a tractable model for the analysis of the relationship between economic growth and the intensive and extensive margins of technology adoption. At the aggregate level, our model is isomorphic to a neoclassical growth model. The microeconomic underpinnings of growth come from technology adoption of firms, both at the extensive and the intensive margin. We use a data set of 15 technologies and 166 countries to estimate the intensive and extensive margin of adoption using the structural equations derived from our model. We find that the variability across countries in the intensive margin is higher than in the extensive margin. The cross country variation in intensive margin of adoption accounts for around $40 \%$ of the variation in income per capita.
\end{abstract}

Diego A. Comin

Harvard Business School

Soldiers Field

Boston, MA 02163

and NBER

dcomin@hbs.edu

Martí Mestieri

MIT

mestieri@mit.edu 
Either as a fundamental or as a channel that amplifies other fundamentals (e.g., institutions), technology is surely important to understanding why there are rich and poor countries. However, several factors have limited economists' ability to assess its importance quantitatively. Broadly speaking, the goal of this paper is to overcome some of these difficulties.

One significant limitation in efforts to assess the role of technology has been the lack of direct measures of technology. Traditionally, technology diffusion has been measured as the share of producers who adopt a given technology (Griliches, 1957, Mansfield, 1961 and Gort and Klepper, 1982). Computing this measure requires firm-level data which are hard to collect for a large number of years, countries, and technologies. Consequently, economists have been unable to measure technology diffusion comprehensively.

Comin and Hobijn (2004) and Comin, Hobijn and Rovito (2006) present a new approach to measuring technology. They measure either the number of units of capital in a country that embody the new technology (e.g., the number of telephones) or the amount of output produced with the new technology (e.g., the tons of steel produced in blast oxygen furnaces). These measures have two advantages over traditional measures of technology diffusion. First, they just require data at the country level. Thus, it is easier to collect them for a large number of countries, technologies and years. ${ }^{1}$ Second, they capture the number of units of the technology adopted by each adopter. ${ }^{2}$

As with any new data set, these new technology measures introduce the challenge of finding ways to extract information relevant to modeling the technology diffusion process. That is, they present the challenge of mapping the data into dimensions that we can interpret through the lens of our models.

Consider Figure 1 for an example of one technology in Comin, Hobijn and Rovito (2006). Figure 1 reports the number of land line phone calls normalized by total output for the United States, Australia, Japan, Malawi, Pakistan and Burkina Faso. These curves roughly appear to be the graphic result of plotting a single curve and then shifting it both horizontally

\footnotetext{
${ }^{1}$ The CHAT data set described in Comin and Hobijn (2009) contains information about the diffusion of 104 technologies in 166 countries over the last 200 years.

${ }^{2}$ As shown by Comin, Hobijn and Rovito (2008), technology measures that include this dimension do not diffuse following a logistic curve which is characteristic of traditional measures (Griliches, 1957).
} 
and vertically. The hypothesis that this apparent graphic result reflects the actual process of technology adoption across countries was broadly confirmed in formal tests conducted in Comin and Hobijn (2010). Assuming this characterization of technology adoption, we can fully describe cross-country differences in technology dynamics if we know what drives the horizontal and vertical shifts in the diffusion curves. Section 1 develops a model based on Comin and Hobijn (2010) that provides a micro-foundation for these shifts.

A technology, in our model, is a group of production methods used to make an intermediate good or provide a service. We consider two aspects of technology adoption, which we call the "extensive" and "intensive" margins. The extensive margin of technology adoption gauges how long it takes a country to adopt a technology. Adopting a production method requires incurring in a fixed investment. The timing of this investment determines the lag with which production methods arrive in a country. In section 2 , we show that the horizontal shifts seen in Figure 1 measure adoption lags. We call this lag the extensive margin of adoption.

Once a technology has been introduced, the intensive margin of adoption captures how many units of the good embodying it are demanded relative to aggregate demand. The intensive margin is determined by the productivity and price of goods that embody the technology and the cost that individual producers face in learning how to use it. Other things equal, these variables produce vertical shifts in the evolution of observable measures of technology adoption such as displayed in Figure 1. We call the vertical shift the intensive margin.

In this paper we pay particular attention to the intensive margin. To be clear, our goal is not to assess how important a particular factor may be in affecting the intensive margin of technology adoption. Instead, we just intend to understand how important crosscountry differences in this margin are in explaining cross-country differences in productivity. Answering this question does not require taking a strong stand on the nature of the drivers of technology adoption.

Little has been known about how significant a role the intensive margin of technology adoption plays in determining overall productivity performance. Clark's (1988) classic study on spinning-machine spindles documents large cross-country differences in the number 
of spindles that each worker operated circa 1900 and argues that this factor was a major contributor to differences in productivity. However, observing more units of a new technology in rich countries is not sufficient to establish the importance of the intensive margin for aggregate productivity, since it could just reflect reverse causation. In other words, higher aggregate demand could lead to the adoption of more units of technology per worker.

Filtering out the effect of aggregate demand on observable measures of technology is a key challenge that any attempt to assess the importance of the intensive margin needs to confront. We follow two different approaches to deal with this issue. First, we use our model predictions to pin down the income elasticity of our technology measures. On a balanced growth path, the income elasticity of demand for the goods embodying technology must equal one. Using this restriction we can filter out the effect of aggregate demand on technology adoption and then use the model to formalize the intuitions described above and identify the intensive and extensive margins of adoption.

Our second approach relaxes the restrictions of a balanced growth path (despite its appeal over long periods we study) to check the robustness of our findings. Here we use the time series dimension of our panel to estimate the income elasticity of demand for goods embodying a technology. Because of the need for long time series to carry out this exercise and because we want to reduce possible biases in the estimates of the intensive margin, ${ }^{3}$ we proceed in two steps. First, we estimate the income elasticity of demand for goods embodying a technology using only U.S. data, and then we impose this estimate on the other countries to estimate the intensive adoption margin and the adoption lags for each technology-country pair.

We use data for 15 technologies and 166 countries, as in Comin, Hobijn, and Rovito (2006). Our data cover major technologies related to transportation, telecommunication, information technology, health care, steel production, and electricity. We obtain precise and plausible estimates of the adoption lags for two thirds of the 1294 technology-country pairs for which we have sufficient data.

Our exploration of the intensive margin of adoption, complementing Comin and Hobijn's (2010) analysis of the extensive margin, delivers four main findings. First, the magnitude

\footnotetext{
${ }^{3}$ See section 2.3 for more details.
} 
of cross-country differences in the intensive margin of adoption and adoption lags are large. On average, they are $20 \%$ larger than the cross-country dispersion in per capita income. Second, there are significant differences across technologies in the cross-country dispersion in the intensive margin. For example, the dispersion in electricity and passenger rail represents $40 \%$ of the dispersion in per capita income, while in blast oxygen steel represents $170 \%$ of the dispersion in income. Third, a variance decomposition reveals that $33 \%$ of the variation in the intensive margin can be attributed to cross-technology variation, $43 \%$ can be attributed to cross-country variation, and the remaining $23 \%$ is not explained by these two factors. Fourth, the cross-country dispersion in adoption lags has declined monotonically over time. Specifically, for every decade later that a technology has been invented, the dispersion has been two years smaller. In contrast, we do not observe any cross country convergence in the intensive margin of adoption.

Our model is similar at the aggregate level to the neoclassical growth model, except that in our model the level of total factor productivity (TFP) is endogenous. In particular, TFP depends on both the intensive and extensive margins of technology adoption. We use this result to assess the magnitude of the cross-country differences in labor productivity that our estimated differences in the intensive margin generate. We find that differences in the intensive margin of adoption account for $44 \%$ of cross-country differences in income per capita. As our model makes clear, these effects could be fundamentally driven by differences in the costs individual producers face in adopting the new technologies or by differences in the overall efficiency of the economy that affect the intensity of adoption.

Finally, we show that the empirical results obtained in the baseline model hold when we allow for non-homothetic production functions that do not pin down the income elasticity of demand for goods embodying a new technology. For instance, the intensive margin still accounts for $52 \%$ of the cross-country variation in income per capita.

This paper is related to three strands of the literature. First, macroeconomic models of technology adoption (e.g., Parente and Prescott, 1994, and Basu and Weil, 1998) have tried to understand the role of technology in determining TFP. However, these studies have used an abstract concept of technology that is hard to match with data. Second, the applied microeconomic technology diffusion literature (Griliches, 1957, Mansfield, 1961, and Gort and 
Klepper, 1982, among others) has focused on estimating diffusion curves for technologies in different countries. However, these studies have only been able to investigate a relatively small number of technologies and countries. Moreover, the diffusion curves are purely statistical descriptions, not embedded in an aggregate model. Hence, it is difficult to use them to explore the aggregate implications of the findings.

Finally, the closest reference to this paper is Comin and Hobijn (2010). This paper differs from it in at least three important ways. First, our model provides a micro-foundation for the intensive margin of adoption as well as for the extensive margin. Second, in our empirical analysis we estimate and analyze the intensive margin of adoption. Third, we explore the robustness of our findings about the two margins of adoption by relaxing the balanced growth restriction and allowing the income elasticity of the demand for the technology to be endogenous.

The paper is divided into four sections. Section 1 sets out a one-sector neoclassical growth model featuring intensive and extensive margins of adoption. Section 2 describes the diffusion patterns of technology under the balanced growth path assumption, derives structural equations that can be estimated from the data, and explains how the margins of adoption are identified. Section 3 presents the results of the estimation, and Section 4 concludes.

\section{A one-sector growth model with extensive and intensive technology adoption}

We next present a one-sector growth model with endogenous technology adoption at the extensive and intensive margins. The model maps the adoption margins into the time-path of observable measures of technology diffusion and illustrates how each adoption margin affects endogenous TFP differentials. In what follows, we omit the time subscript, $t$, where obvious. 


\subsection{Preferences}

A measure one of households populates the economy. They inelastically supply one unit of labor every instant, at the real wage rate $W$, and derive the following utility from their consumption flow

$$
U=\int_{0}^{\infty} e^{-\rho t} \ln \left(C_{t}\right) d t .
$$

Here $C_{t}$ denotes per capita consumption and $\rho$ is the discount rate. We further assume that capital markets are perfectly competitive and that consumers can borrow and lend at the real rate $\widetilde{r}$.

\subsection{Production}

\section{Technology:}

Each instant, a new production method appears exogenously. We call these production methods, technology vintages or simply vintages. Production methods are capital embodied. The set of vintages available at time $t$ is given by $\bar{V}=(-\infty, t]$. The productivity embodied in new vintages grows at a rate $\gamma$ across vintages, such that

$$
Z_{v}=Z_{0} e^{\gamma v}
$$

Note that $Z_{v}$ is constant over time. This characterizes the evolution of the world technology frontier. We shall choose the normalization parameter $Z_{0}$ such that vintage $\underline{v}$ has productivity $Z_{\underline{v}} \cdot{ }^{4}$

A country does not necessarily use all the capital vintages that are available in the world because, as we discuss below, making them available for production is costly. The set of vintages actually used is given by $V=(-\infty, t-D]$. Here $D \geq 0$ denotes the adoption lag. That is, the amount of time between when the best technology in use in the country became available and when it was introduced in the country.

In order to map the model into the data, we introduce the concept of technology. A technology is a set of production methods used to produce closely related intermediates. To

\footnotetext{
${ }^{4}$ This implies that $Z_{0}=Z_{\underline{v}} e^{-\gamma \underline{v}}$.
} 
simplify the exposition, we consider only two technologies: an old one, denoted by $o$, and a new one, denoted by $n$. The old technology consists of the production methods introduced up till a fixed time $\underline{v}$, such that the set of vintages associated with the old technology is $V_{o}=(-\infty, \underline{v}$. The new technology consists of the newest production methods, invented after $\underline{v}$, such that it covers $V_{n}=(\underline{v}, t-D]$.

\section{Output:}

The output associated to a technology $\tau, Y_{\tau}$, is given by:

$$
Y_{\tau}=\left(\int_{V_{\tau}} Y_{v}^{\frac{1}{\mu}} d v\right)^{\mu}, \quad \tau \in\{o, n\},
$$

where $Y_{v}$ denotes the intermediate output produced using technology vintage $v$. Final output $Y$, is produced competitively with the following production function:

$$
Y=\left(\int_{-\infty}^{t-D} Y_{v}^{\frac{1}{\mu}} d v\right)^{\mu}=\left(\sum_{\tau \in\{0, n\}} Y_{\tau}^{\frac{1}{\mu}}\right)^{\mu} .
$$

Once a technology vintage $v$ is brought to the country, producers can find distinct ways to use it. Because each application developed solves a new problem, the larger the number of applications developed, $N_{v}$, the more efficient the production of intermediate service $v$ is. In other words, there are efficiency gains from developing more applications.Each application yields a differentiated output, $Y_{v i}$. Differentiated outputs are produced monopolistically. A competitive producer then aggregates these outputs in the form of intermediate $v, Y_{v}$, as follows: ${ }^{5}$

$$
Y_{v}=N_{v}^{-\left(\mu-\mu^{\prime}\right)}\left(\int_{0}^{N_{v}} Y_{v i}^{\frac{1}{\mu}} d i\right)^{\mu} \text {, with } \mu>\mu^{\prime}>1 .
$$

Output $Y_{v i}$ is produced by combining labor and capital, $K_{v i}$, that embodies production method, $v$, as follows:

$$
Y_{v i}=Z_{v} L_{v i}^{1-\alpha} K_{v i}^{\alpha},
$$

Capital goods production and taxes:

\footnotetext{
${ }^{5}$ This specification is similar to Benassy (1996). The assumption that $\mu>\mu^{\prime}$ ensures that the profits of a individual producer decline with $N_{v}$.
} 
Capital goods are produced by monopolistic competitors. Each of them holds the patent of the capital good used for a particular production method $v$. It takes one unit of final output to produce one unit of capital of any vintage. This production process is assumed to be fully reversible. For simplicity, we assume that there is no physical depreciation of capital. The capital goods suppliers rent out their capital goods at the rental rate $\phi_{R} R_{v} . R_{v}$ is the price received by the capital goods producer, while the wedge $\phi_{R}$ captures a tax on the price of capital that the government rebates back to the consumers with a lump sum transfer. $\phi_{R}$ is constant across vintages and over time. Below we show that $\phi_{R}$ can capture a wide range of institutional distortions that affect the efficiency of the economy.

\section{Technology adoption costs:}

There are two types of adoption costs. The cost of bringing to the country the production method associated with a capital vintage, $\Gamma_{v t}^{e}$, and the cost incurred by each individual producer to find a distinct application of a production method that is already available, $\Gamma_{v t}^{i}$. We define the former as the extensive and the latter as the intensive adoption costs. Both of these are sunk costs. The extensive cost of adopting vintage $v$ at time $t$ is given by (6) while the intensive cost of adoption is given by (7).

$$
\begin{gathered}
\Gamma_{v t}^{e}=\frac{\alpha}{\epsilon} \bar{\Psi}\left(1+b_{e}\right)\left(\frac{Z_{v}}{Z_{t}}\right)^{\frac{1+\vartheta}{\mu-1}}\left(\frac{Z_{t}}{A_{t}}\right)^{\frac{1}{\mu-1}} Y_{t}, \text { where } \vartheta>0 \\
\Gamma_{v t}^{i}=\frac{\mu-1}{\mu} \bar{\Psi}\left(1+b_{i}\right)\left(\frac{Z_{v}}{Z_{t}}\right)^{\frac{1}{\mu-1}}\left(\frac{Z_{t}}{A_{t}}\right)^{\frac{1}{\mu-1}} Y_{t} .
\end{gathered}
$$

In these expressions, $A_{t}$ is the aggregate level of TFP to be defined below, $b_{e}, b_{i}$, and $\bar{\Psi}$ are constants. The parameters $b_{e}$ and $b_{i}$ reflect barriers to adoption for the agent that adapts the technology to the idiosyncrasies of the country or for individual producers that find a profitable use for the technology. $\bar{\Psi}$ is the steady state stock market capitalization to GDP ratio and is included for normalization purposes. The term $\left(Z_{v} / Z_{t}\right)$ captures the idea that it is more costly to adopt technologies the higher is their productivity relative to the productivity of the frontier technology. The last two terms capture that the cost of adoption is increasing in the market size. We choose these formulations because, just like the adoption 
cost function in Parente and Prescott (1994), they yield an aggregate balanced growth path. ${ }^{6}$

\subsection{Factor demands, output, and optimal adoption}

The demand for the output produced with vintage $v$ is:

$$
Y_{v}=Y\left(P_{v}\right)^{-\frac{\mu}{\mu-1}}, \text { where } P=\left(\int_{v \in V} P_{v}^{-\frac{1}{\mu-1}} d v\right)^{-(\mu-1)} .
$$

We use the final good as the numeraire good throughout our analysis and normalize its price to $P=1$. The demand faced by the $i^{\text {th }}$ producer of differentiated output associated to vintage $v$ is:

$$
Y_{v i}=Y_{v}\left(\frac{P_{v i}}{P_{v}}\right)^{-\frac{\mu}{\mu-1}} N_{v}^{-\frac{\mu-\mu^{\prime}}{\mu-1}}, \text { where } P_{v}=N_{v}^{\frac{\mu-\mu^{\prime}}{\mu-1}}\left(\int_{0}^{N_{v}} P_{v i}^{-\frac{1}{\mu-1}} d i\right)^{-(\mu-1)}
$$

Note that all producers of differentiated outputs associated to a given vintage face the same demand and have access to the same technology. As a result, they will charge the same price which is given by a constant markup, $\mu$, times the marginal cost of production:

$$
P_{v i}=\mu\left[\frac{1}{Z_{v}}\left(\frac{\phi_{R} R_{v}}{\alpha}\right)^{\alpha}\left(\frac{W}{1-\alpha}\right)^{1-\alpha}\right] \text {, for } i \in\left[0, N_{v}\right]
$$

where $R_{v}$ is the rental price of a unit of capital that embodies vintage $v, \phi_{R}$ is a tax on capital, and $W$ is the wage rate. From (9), this implies that

$$
P_{v}=N_{v}^{-\left(\mu^{\prime}-1\right)} P_{v i}
$$

The revenue share of capital is $\alpha$ and labor exhaust the remaining revenue. This implies

\footnotetext{
${ }^{6}$ It could of course be the case that the linearity in the adoption cost function is violated for some particular technology for some particular country, without necessarily violating balanced growth, but to the extent that we are documenting adoption lags across many technologies this is perhaps not so critical.
} 
that the total demand faced by the producer of the capital good that embodies vintage $v$ is:

$$
\begin{aligned}
K_{v} & =\int_{0}^{N v} K_{v i} d i=\frac{\alpha P_{v} Y_{v}}{\phi_{R} R_{v}} \\
& =Y\left(\frac{Z_{v}}{\mu}\right)^{\frac{1}{\mu-1}} N_{v}^{\frac{\mu^{\prime}-1}{\mu-1}}\left(\frac{(1-\alpha)}{W}\right)^{\frac{1-\alpha}{\mu-1}}\left(\frac{\alpha}{\phi_{R} R_{v}}\right)^{\epsilon} \text {, where } \epsilon \equiv 1+\frac{\alpha}{\mu-1} .
\end{aligned}
$$

The supplier of each capital good takes as given the number of differentiated output producers but recognizes that the rental price he charges for the capital good, $R_{v}$, affects the price of the output associated with the capital good and, therefore, its demand, $Y_{v}$. The price elasticity of demand she faces, $\epsilon$, is constant. As a result, the profit maximizing rental price equals a constant markup times the marginal production cost of a unit of capital, which we assume is equal to a unit of final output.

Because of the durability of capital and the reversibility of its production process, the per-period marginal production cost of capital is the user-cost of capital. Thus, the rental price that maximizes the profits accrued by the capital good producer is

$$
R_{v}=R=\frac{\epsilon}{\epsilon-1} \widetilde{r}
$$

where $\frac{\epsilon}{\epsilon-1}$ is the constant gross markup factor.

Aggregate representation:

Our model has the following aggregate representation of production:

$$
Y=A K^{\alpha} L^{1-\alpha}, \text { where } K \equiv \int_{-\infty}^{t} K_{v} d v, L \equiv \int_{-\infty}^{t} L_{v} d v
$$

Aggregate TFP, A, can be expressed as

$$
A=\left[\int_{-\infty}^{t-D}\left(N_{v}^{\mu^{\prime}-1} Z_{v}\right)^{\frac{1}{\mu-1}} d v\right]^{\mu-1}
$$

Optimal adoption:

The flow profits accrued by producers of differentiated outputs associated with vintage $v$ are 
equal to

$$
\pi_{v i}=\frac{\mu-1}{\mu} P_{v i} Y_{v i}=\frac{\mu-1}{\mu} Y\left(\frac{Z_{v}}{A}\right)^{\frac{1}{\mu-1}} N_{v}^{-\frac{\mu-\mu^{\prime}}{\mu-1}}
$$

The market value of each differentiated output producer equals the present discounted value of the flow profits. That is,

$$
M_{v i, t}=\int_{t}^{\infty} e^{-\int_{t}^{s} \widetilde{r}_{s^{\prime}} d s^{\prime}} \pi_{v i s} d s=\frac{\mu-1}{\mu}\left(\frac{Z_{v}}{Z_{t}}\right)^{\frac{1}{\mu-1}}\left(\frac{Z_{t}}{A_{t}}\right)^{\frac{1}{\mu-1}} N_{v}^{-\frac{\mu-\mu^{\prime}}{\mu-1}} \Psi_{t} Y_{t}
$$

where

$$
\Psi_{t}=\left(\frac{\mu-1}{\mu}+\frac{\alpha}{\epsilon}\right) \int_{t}^{\infty} e^{-\int_{t}^{s} \widetilde{s}_{s^{\prime}} d s^{\prime}}\left(\frac{A_{t}}{A_{s}}\right)^{\frac{1}{\mu-1}}\left(\frac{Y_{s}}{Y_{t}}\right)\left(\frac{N_{v}(s)}{N_{v}(t)}\right)^{-\frac{\mu-\mu^{\prime}}{\mu-1}} d s
$$

is the stock market capitalization to GDP ratio.

Optimal adoption implies that, every instant, the value of becoming a user of a technology vintage $v$ does not exceed the intensive cost of adoption. That is, for all vintages, $v$, that are adopted at time $t$

$$
\Gamma_{v}^{i} \geq M_{v i}
$$

Thus, in equilibrium

$$
N_{v}=\left(\frac{\Psi_{t}}{\bar{\Psi}_{t}\left(1+b_{i}\right)}\right)^{\frac{\mu-1}{\mu-\mu^{\prime}}} .
$$

Given $N_{v}$, the flow profits that the capital goods producer of vintage $v$ earns are equal to

$$
\pi_{v}=\frac{\alpha}{\epsilon \phi_{R}} P_{v} Y_{v}=\frac{\alpha}{\epsilon} N_{v}^{\frac{\mu^{\prime}-1}{\mu-1}}\left(\frac{Z_{v}}{A}\right)^{\frac{1}{\mu-1}} Y
$$

The market value of each capital goods supplier equals the present discounted value of the flow profits. That is,

$$
M_{v, t}=\int_{t}^{\infty} e^{-\int_{t}^{s} \widetilde{r}_{s^{\prime}} d s^{\prime}} \pi_{v s} d s=\frac{\alpha}{\epsilon \phi_{R}} N_{v}^{\frac{\mu^{\prime}-1}{\mu-1}}\left(\frac{Z_{v}}{Z_{t}}\right)^{\frac{1}{\mu-1}}\left(\frac{Z_{t}}{A_{t}}\right)^{\frac{1}{\mu-1}} \Psi_{t} Y_{t} .
$$

Optimal adoption implies that, every instant, all the vintages for which the value of the firm that produces the capital good is at least as large as the adoption cost will be adopted. That 
is, for all vintages, $v$, that are adopted at time $t$

$$
\Gamma_{v}^{e} \geq M_{v}
$$

This holds with equality for the best vintage adopted if there is a positive adoption lag.

The adoption lag that results from this condition equals

$$
D_{v}=\max \left\{\frac{\mu-1}{\gamma \vartheta}\left[\ln \left(1+b_{e}\right)+\ln \phi_{R}-\frac{\mu^{\prime}-1}{\mu-1} \ln N_{v}+(\ln \bar{\Psi}-\ln \Psi)\right], 0\right\} \equiv D
$$

and is constant across vintages, $v .^{7}$ The lag with which new vintages are adopted is increasing in the adoption costs, $b_{e}$, and the tax wedge, $\phi_{R}$, is decreasing in $N_{v}$ and in the deviation of the stock market to output ratio from its steady state level. As shown in equation (16), the number of producers that develop distinct uses for technology vintage $v, N_{v}$, declines with the intensive cost of adoption, $b_{i}$, and increases with the deviation of the stock market to output ratio from the balance growth level. ${ }^{8}$

Conversely, there are several significant factors that do not influence the adoption decisions. First, given the specifications of the production function and the costs of adoption, the market size symmetrically affect the benefits and costs of adoption at both the intensive and extensive margins. Hence, variation in market size does not affect the timing of adoption, $D$, and the number of producers that use a new vintage, $N_{v}$. By the same token, the adoption margins are not affected by the productivity of technology at time zero, $Z_{0}$. Second, since on the balanced growth path $\Psi=\bar{\Psi}$, the steady-state adoption lags and number of producers do not depend on the stock market to output ratio.

These observations together with equation (12) help us understand what drives aggregate TFP in this model. Three factors can drive cross-country differences in TFP: The adoption lag, the number of producers that adopt each technology vintage, and the normalized pro-

\footnotetext{
${ }^{7}$ In what follows we focus on the interior case where $\Gamma_{t \tau} \leq M_{t \tau}$.

${ }^{8}$ Note that $\phi_{R}$ does not affect the intensity of adoption as measured by the number of producers that adopt a new vintage. That is the case because, from the perspective of the potential producers of differentiated outputs, $\phi_{R}$ only affects aggregate demand. Aggregate demand, in turn, has a symmetric effect on the costs and benefits of adopting the vintage for the differentiated output producers. Instead, corporate income taxes (or expropriation risk) also affect the profit margin net of taxes. This asymmetric effect would affect the number of producers that adopt the new vintage.
} 
ductivity level of the initial vintage. Note that, $Z_{0}$ affects directly aggregate TFP but, as mentioned above, has no effect through $D$ or $N_{v}$. The costs of adopting new technologies affect TFP because they influence the range of technologies available for production and how many different applications are developed. Finally, the tax wedge (and other related frictions) only affect aggregate TFP through their effect on the adoption decisions.

\section{Diffusion of the new technology}

We define the equilibrium of this economy in Appendix B. In what follows, we focus on the balanced growth path of the economy. ${ }^{9}$ Along the balanced growth path, adoption lags, $D$, are constant, the number of adopters that adopt each vintage once it is available in the country is constant and equal to $N$, and the economy grows at a constant rate equal to $\gamma /(1-\alpha) \cdot{ }^{10}$

So far, we have derived expressions for output and capital at the vintage level. However, because of the nature of available data, we are interested in the total demand for capital goods and the output produced with the production methods that make up the new technology $\tau=n$. We can express output produced with technology $\tau$ in the following Cobb-Douglas form

$$
Y_{\tau}=A_{\tau} K_{\tau}^{\alpha} L_{\tau}^{1-\alpha}
$$

where

$$
\begin{aligned}
K_{\tau} & \equiv \int_{v \in V_{\tau}} K_{v} d v, L_{\tau} \equiv \int_{v \in V_{\tau}} L_{v} d v \\
\text { and } A_{\tau} & =\left(\int_{V_{\tau}}\left(N_{v}^{\mu^{\prime}-1} Z_{v}\right)^{\frac{1}{\mu-1}} d v\right)^{\mu-1}
\end{aligned}
$$

Substituting in for $Z_{v}$, and recognizing that, along the balanced growth path, the adoption lag and the number of differentiated producers are constant and equal to $D$ and $N_{n}$,

\footnotetext{
${ }^{9}$ The transitional dynamics of the model are similar to the one described in the working paper version of Comin and Hobjin (2009).

${ }^{10}$ Of course, $D$ and $N$ could differ across countries.
} 
respectively, we can express the endogenous level of TFP for technology $\tau=n$ at time $t$ as

$$
A_{n}=\left(\frac{\mu-1}{\gamma}\right)^{\mu-1} \underbrace{N_{n}^{\mu^{\prime}-1}}_{\text {intensity of adoption }} Z_{\underline{v}} \underbrace{e^{\gamma(t-D-\underline{v})}}_{\text {embodiment effect }}[\underbrace{\left[1-e^{-\frac{\gamma_{\tau}}{\mu-1}(t-D-\underline{v})}\right]^{\mu-1}}_{\text {variety effect }} .
$$

The path of the new technology TFP is driven by the adoption margins. First, there are efficiency gains from the number of producers that adopt a given vintage. This affects the level of technology through the 'intensity of adoption' term in (23). The trend in TFP is driven by the economy-wide adoption of new, more productive, vintages. The adoption lag determines the best vintage adopted and affects the level of TFP through the 'embodiment effect' term in (23). Finally, adoption lags also drive the curvature of $A_{n}$ at a given moment in time. The marginal productivity gain from adopting new vintages decreases as more vintages are adopted. Because the adoption lag determines how far in the adoption process a country is at time $t$, they affect the evolution of the slope through the 'variety effect'. Graphically, this effect is captured by horizontal shifts in the path of $A_{n}$ as adoption lags vary. We shall use this result to identify the adoption lags in the data.

These properties of the path for the level of TFP for technology $\tau$ affects the output and capital associated with the technology through its effect on the marginal cost of production of the technology-specific output measured by the price $P_{\tau}$.

$$
P_{\tau}=\frac{\mu}{A_{\tau}}\left(\frac{W}{1-\alpha}\right)^{1-\alpha}\left(\frac{\phi_{R} R}{\alpha}\right)^{\alpha}
$$

\subsection{Empirical application}

Our goal is to estimate the intensity of adoption and adoption lags for the different technologycountry pairs in our data set. We extend the results above by allowing multiple sectors, each adopting a new technology. ${ }^{11}$ We do that with a nested CES aggregator, where $\frac{\theta}{\theta-1}$ reflects the between sectors elasticity of demand and $\frac{\mu}{\mu-1}$ is, just as in the one-sector model, the within sector elasticity of demand. We allow $\frac{\theta}{\theta-1}$ to vary across sectors. Further, we allow the growth rate of embodied technological change, $\gamma_{\tau}$, and the invention date, $\underline{v}_{\tau}$, to vary

\footnotetext{
${ }^{11}$ Comin and Hobijn (2008) derive the multi-sector version of a similar model in detail.
} 
across technologies. We denote the technology measures for which we derive reduced form equations by $m_{\tau} \in\left\{y_{\tau}, k_{\tau}\right\}$. Small letters denote logarithms.

These modifications yield the following demand for technology $\tau$ output

$$
y_{\tau}=y-\frac{\theta}{\theta-1} p_{\tau}
$$

Combining that with the intermediate goods price (24)

$$
p_{\tau}=-\alpha \ln \alpha-a_{\tau}+(1-\alpha)(y-l)+\alpha r+\alpha \ln \phi_{R}
$$

we obtain the reduced form equation (27) for $y_{\tau}$.

$$
y_{\tau}=y+\frac{\theta}{\theta-1}\left[a_{\tau}-(1-\alpha)(y-l)-\alpha r+\alpha \ln \alpha-\alpha \ln \phi_{R}\right]
$$

Similarly, we obtain the reduced form equation for $k_{\tau}$ by combining the log-linear capital demand equationwith (25) and (26),

$$
k_{\tau}=y+\frac{1}{\theta-1}\left[a_{\tau}-(1-\alpha)(y-l)-\alpha r+\alpha \ln \alpha-\alpha \ln \phi_{R}\right]+\ln \alpha-r-\ln \phi_{R}
$$

These expressions depend on the intensive margin and adoption lag $D_{\tau}$ through their effect on the productivity term, $a_{\tau}$. Comin and Hobijn (2010) show that, to a first order approximation,

$$
a_{\tau} \approx\left(\mu^{\prime}-1\right) n_{\tau}+z_{\underline{v}_{\tau}}+(\mu-1) \ln \left(t-T_{\tau}\right)+\frac{\gamma_{\tau}}{2}\left(t-T_{\tau}\right)
$$

where $T_{\tau}=\underline{v}_{\tau}+D_{\tau}$ is the time when the technology is adopted. In this approximation, the growth rate of embodied technological change, $\gamma_{\tau}$, only affects the linear trend in $a_{\tau} \cdot{ }^{12}$

\footnotetext{
${ }^{12}$ Intuitively, when there are very few vintages in $V_{\tau}$ the growth rate of the number of vintages, i.e. the growth rate of $t-T_{\tau}$, is very large and it is this growth rate that drives growth in $a_{\tau}$ through the variety effect. Only in the long-run, when the growth rate of the number of varieties tapers off, the growth rate of embodied productivity, $\gamma_{\tau}$, becomes the predominant driving force over the variety effect.
} 
Substituting this into (25) and (28) yields the following reduced form equation

$$
m_{\tau}=\beta_{1}+y+\beta_{2} t+\beta_{3}\left((\mu-1) \ln \left(t-T_{\tau}\right)-(1-\alpha)(y-l)\right)+\varepsilon_{\tau}
$$

where $\varepsilon_{\tau}$ is the error term. The reduced form parameters are given by the $\beta$ 's. Note that, the homothetic nature of the production function implies that the coefficient of aggregate demand, $y$, is equal to one.

According to our theoretical model, the intercept $\beta_{1}$ is given by the following expression which depends on both the intensive and extensive margins of adoption,

$$
\begin{aligned}
& \beta_{1}^{y}=\frac{\theta}{\theta-1}\left[\left(\left(\mu^{\prime}-1\right) n_{\tau}+z_{\underline{v}_{\tau}}\right)-\frac{\gamma}{2} T-\alpha\left(r+\ln \phi_{R}-\ln (\alpha)\right)\right], \\
& \beta_{1}^{k}=\frac{1}{\theta-1}\left[\left(\left(\mu^{\prime}-1\right) n_{\tau}+z_{\underline{v}_{\tau}}\right)-\frac{\gamma}{2} T-\alpha\left(r+\ln \phi_{R}-\ln (\alpha)\right)\right]-r-\ln \phi_{R} .
\end{aligned}
$$

We define the intensive margin of adoption of technology $\tau$ in country $j$ as

$$
\triangle_{j \tau}=\left(\left(\mu^{\prime}-1\right) n_{\tau}+z_{\underline{v}_{\tau}}\right)-\alpha\left(r+\ln \phi_{R}-\ln (\alpha)\right) .
$$

Three different factors affect the intensive margin of adoption: the number of adopters of the technology, $n_{\tau}$, the normalized productivity level of the technology, $z_{\underline{v}_{\tau}}$, and the distortions in the price of capital, $r+\ln \phi_{R}$.

\subsection{Identification and estimation procedure}

We use the reduced form equation in (30) to identify the adoption lags and the intensity of adoption. To this end, we assume that preference parameters $(\rho)$ and technology parameters other than adoption costs (i.e., $\theta, \mu, \mu^{\prime}, \gamma \alpha$, and $z_{\underline{v}_{\tau}}$ ) are the same across countries. This implies that the equilibrium interest rate $(r)$ is also the same across countries. ${ }^{13}$ The distortions that affect the efficiency of the economy $\left(\phi_{R}\right)$ and the adoption cost parameters $\left(b_{e}\right.$ and $\left.b_{i}\right)$ can vary across countries. As a result, the adoption lags $\left(D_{\tau}\right)$ and the number of producers that adopt a technology $(n)$ can also differ across countries.

\footnotetext{
${ }^{13}$ Our identification strategy is unaffected if interest rates, $r$, and the normalized productivity level for the new technologies, $z_{\underline{v}_{\tau}}$, varied across countries.
} 
These assumptions impose some cross-country parameter restrictions. Since the intercept term, $\beta_{1}$, depends on $n, D_{\tau}$ and $\phi_{R}$, it can vary across countries. The trend-parameter, $\beta_{2}$, just depends on $\alpha$ and $\gamma_{\tau}$, so it is assumed to be constant across countries. ${ }^{14} \beta_{3}$ only depends on the technology parameter, $\theta$, and is therefore assumed to be constant across countries. We do not estimate $\mu$ and $\alpha$. Instead, we calibrate $\mu=1.3$, based on the estimates of the markup in manufacturing from Basu and Fernald (1997), and $\alpha=0.3$ consistent with the post-war U.S. labor share. ${ }^{15}$

The parameter $\beta_{1}$ is a technology-country specific constant. Therefore, it can be identified by a technology-country fixed effect. Once we have an estimate of $\beta_{1}$, we still need an estimate of the adoption lags to obtain an estimate of the intensive margin of adoption. We follow Comin and Hobijn (2010) and identify the adoption lags through the non-linear trend component in equation (30), which reflects the variety effect. Intuitively, after controlling for the observables such as GDP or labor productivity, only the adoption lag affects the curvature of $m_{\tau}$. That implies that, ceteris paribus, if we see two countries one with a steeper diffusion curve than the other at a given point in time, this means that the former started adopting the technology later.

For each technology, we report the intensive margin measures relative to the U.S. Note that our estimates of $\beta_{1}$ in (31) and (32) are not directly comparable for technologies measured with capital and output variables. To construct comparable measures of intensive margin of adoption, we need to eliminate the differential effect of $\phi_{R}$ that appears on the technologies measured using capital. To this end, we regress, for each country, the intercepts in (31) and (32) on a dummy variable that takes value of 1 if the technology is measured in capital units. The coefficient on the dummy captures the differential effect of $\phi_{R}$. We then subtract the dummy coefficient from $\beta_{1}^{k}$, and correct for the factors $\theta /(\theta-1)$ and $1 /(\theta-1)$ to obtain the measure of the intensive margin in $(33) \cdot{ }^{16,17}$

\footnotetext{
${ }^{14}$ The output elasticity of capital is one minus the labor share in our model. Gollin (2002) provides evidence that the labor share is approximately constant across countries.

${ }^{15}$ As argued by Comin and Hobijn (2008), the estimates of the adoption parameters are very robust to alternative calibrations of these parameters.

${ }^{16}$ The parameter $\theta$ is computed as the average (across technologies) implied estimate from the estimates of $\beta_{3}$ and it is equal to 1.31 for the homothetic case and 1.14 for the non-homothetic case.

${ }^{17}$ An alternative approach could be to take advantage of the fact that we have two measures of railways that are measured as output (passengers and freight) and one that is measured as capital (rail lines). Under
} 
This identification strategy assumes that the underlying curvature of the diffusion curves is the same across countries. This assumption would be violated, for example, if the efficiency of an economy increased over time non-linearly inducing a similar pattern in the technology measure. Of course, a priori, there is no reason why the distortions in the economy evolve to induce such a specific pattern of adoption rather than affecting the trend or adding noise to the evolution of technology. Nevertheless, Comin and Hobijn (2010) take seriously this hypothesis and test formally the identification assumption by allowing $\beta_{3}$ to vary across countries. Then, they see how often they can reject the null that the unrestricted and the restricted estimates are the same (i.e. $\hat{\beta}_{3}^{u}=\hat{\beta}_{3}$ ). They find that they cannot reject the null in two thirds of the technology-country pairs considered. Further, the estimated adoption lags in the restricted and unrestricted specifications are very highly correlated suggesting that, effectively, the deviations from a constant curvature pattern are not quantitatively important.

Because the adoption lag is a parameter that enters non-linearly in (30) for each country, estimating the system of equations for all countries together is practically not feasible. Instead, we take a two-step approach. We first estimate equation (30) using only data for the U.S. This provides us with estimates of the values of $\beta_{1}$ and $D_{\tau}$ for the U.S. as well as estimates of $\beta_{2}$ and $\beta_{3}$ that should hold for all countries. In the second step, we separately estimate $\beta_{1}$ and $D_{\tau}$, using (30) conditional on the estimates of $\beta_{2}$ and $\beta_{3}$ based on the U.S. data, for all the countries in the sample besides the U.S.

Besides practicalities, this two-step estimation method is preferable to a system estimation method for two other reasons. First, in a system estimation method, data problems for one country affect the estimates for all countries. Since we judge the U.S. data to be most reliable, we use them for the inference on the parameters that are constant across countries. Second, our model is based on a set of stark neoclassical assumptions. These assumptions are more applicable to the low frictional U.S. economic environment than to that of countries in which capital and product markets are substantially distorted. Thus, if we think that our

the plausible assumption that the average intercept of the output measures (passenger and freight measures) corresponds to the rail line measure used in the country, we can back out the additional effect of $\phi_{R}$ on the capital measures of technology. Then, we can subtract this additional effect from the other capital measures and can construct comparable measures of the intensive margin. The results we obtain using this procedure are similar to the ones reported in the main text. 
reduced form equation is more likely to be mis-specified for some countries other than the U.S., including them in the estimation of the joint parameters would affect the results for all countries.

We estimate all the equations using non-linear least squares. Since we estimate $\beta_{3}$ for the U.S., this means that the identifying assumption that we make is that the logarithm of per capita GDP in the U.S. is uncorrelated with the technology-specific error, $\varepsilon_{\tau}$. However, because of the cross-country restrictions we impose on $\beta_{3}$, the risk of simultaneity bias is not a concern for all the other countries in our sample.

\subsection{Non-homotheticities}

One general concern in structural estimation exercises is model mis-specification. In the context of our model, the place where this concern probably is more relevant is in the elasticity of technology with respect to income. For our model to have a balanced growth path, the production functions need to be homothetic. This implies that the income elasticity of technology measures is equal to one. In this subsection, we explore the implications for the estimated equations (30) if we replace the original production function (3) for a more general specification that allows for non-homotheticities.

Consider the following non-homothetic version of (3)

$$
Y=\frac{1}{\bar{\theta}}\left(\sum_{\tau} \theta_{\tau} Y_{\tau}^{\frac{1}{\theta}}\right)^{\bar{\theta}}
$$

where $\bar{\theta}$ is the long-run average of $\theta_{\tau}$ over $\tau$ so that constant returns to scale are guaranteed (in the long-run),

$$
Y_{\tau}=Y^{\frac{(\bar{\theta}-1) \theta_{\tau}}{\theta\left(\theta_{\tau}-1\right)}} P_{\tau}^{\frac{-\theta_{\tau}}{\theta_{\tau}-1}}
$$

This yields the following reduced form equation

$$
m_{\tau}=\beta_{1}+\beta_{y} y+\beta_{2} t+\beta_{3}\left((\mu-1) \ln \left(t-T_{\tau}\right)-(1-\alpha)(y-l)\right)+\varepsilon_{\tau},
$$

which differs from (30) in that $\beta_{y}$ is not restricted to be equal to 1 . It will be greater than 
one if $\bar{\theta}>\theta_{\tau}$ and smaller otherwise.

As in the homothetic reduced form equation (30), we estimate the coefficients in (34) that depend on technological parameters $\left(\beta_{2}, \beta_{3}\right.$ and $\left.\beta_{y}\right)$ for the U.S. and then impose these estimates in the other countries. The only difference is that now we estimate an additional parameter, $\beta_{y}$.

Using the U.S. estimate of $\beta_{y}$ has several advantages. First, reliable data on U.S. real GDP is available since 1820. This long time-span facilitates the identification. It also ensures that the estimate is based on the various stages of development that the U.S. has gone through over the last two centuries. As a result, it should capture reasonably well the effect of aggregate demand on technology diffusion for countries at different stages of development. Most importantly, since for each technology-country pair, the intensive margin in our model is constant, by exploiting the time series dimension to identify $\beta_{y}$ we avoid the bias due to the potential cross-country correlation between the intensive margin of adoption and income.

Identifying $\beta_{y}$ using only the time series dimension is not trivial for two reasons. First, since $\gamma_{\tau}$ may differ across technologies, when estimating $\beta_{2}$ we must include a time trend for each technology. Since in the long run log GDP is approximately linear, GDP and time are co-linear over very low frequencies. Second, most technologies in our sample are embodied in capital goods. The high cyclicality and volatility of investment shall induce a high estimate of $\beta_{y}$. This estimate however, would capture the cyclical properties of capital rather than the effect of aggregate demand on our technology measures at lower frequencies.

To overcome these two difficulties, we use a Hodrick-Prescott (HP) filter to decompose log of real GDP into a high frequency component and a 'trend'. As is well known, ${ }^{18}$ trends that result from HP filters have significant fluctuations at medium term frequencies. ${ }^{19}$ By exploiting this variation, we could in principle identify $\beta_{y}$. Thus, we introduce separately the high frequency component and the 'trend' in log real GDP and estimate a different elasticity for each. ${ }^{20,21}$ To identify $\beta_{y}$ in our data, we estimate simultaneously the system of equations

\footnotetext{
${ }^{18}$ E.g. Comin and Gertler (2006).

${ }^{19}$ In the context of this exercise, medium term frequencies means cycles with periods between 8 years and infinity.

${ }^{20}$ We have obtained very similar results when including only the 'trend' component of GDP.

${ }^{21}$ As conjectured, the short-run elasticity is significantly higher, capturing adjustment over the business
} 
(34) for all the U.S. technologies.

Though in our model the parameters that determine the intensive margin are fixed, it is instructive to consider how will our estimate of $\beta_{y}$ be affected if they vary in the data. The first thing to realize is that institutions, human capital and other factors that may affect the costs of adoption at the intensive margin in the U.S. have changed very slowly. As a result, this may have effects on our technology measures and on GDP only at very low frequencies. ${ }^{22}$ These frequencies are so low that most of these effects will be captured by the time trends and will have little effect on the estimate of $\beta_{y}$.

Note further that, since naturally changes in institutions or variables that affect adoption costs would induce a positive co-movement between GDP and technology, the small bias induced on $\beta_{y}$ would be upwards. As a result, when identifying the intensive margin we would filter too much aggregate demand inducing a lower cross-country dispersion in the intensive margin. That is, the bias in $\beta_{y}$ would bias downwards the importance of the intensive margin for development.

\section{Results}

We consider data for 166 countries and 15 major technologies, that span the period from 1820 through 2003. The technologies can be classified into 6 categories; $(i)$ transportation technologies, consisting of steam and motor-ships, passenger and freight railways, cars, trucks, and passenger and freight aircraft; $(i i)$ telecommunication, consisting of telegraphs, telephones, and cellphones; (iii) information technology, consisting of PCs and Internet users; (iv) medical technology, namely MRI scanners; $(v)$ steel produced using blast oxygen furnaces; (vi) electricity.

The technology measures are taken from the CHAT data set. ${ }^{23}$ Real GDP and population data are from Maddison (2007). Appendix A contains a brief description of each of the 15 technology variables used. For our estimation, we only consider country-technology combinations for which we have more than 10 annual observations. There are 1298 such

cycle.

${ }^{22}$ One example would be expansion of high school enrollment in the U.S. between 1910 and 1940 .

${ }^{23}$ See Comin, Hobijn and Rovito (2009). 
pairs in our data. The third column of Table 1 lists, for each technology, the number of countries for which we have enough data.

We follow Comin and Hobijn (2010) and analyze only the technology-country pairs for which we have plausible and precise estimates of the adoption lags. These are estimates with an adoption date later than the invention year plus 10, and with small standard errors. ${ }^{24}$ We have plausible and precise estimates for 837 technology-country pairs, which represent approximately two thirds of the total.

\subsection{Estimated Intensive Margin}

\section{Dispersion}

Table 1 presents the descriptive statistics of our estimates of the intensive margin of adoption relative to the United States. The fifth column reports the cross-country average. This statistic is negative for all the technologies but ships and freight railways. This means that for all the technologies but these two, the U.S. intensive margin is higher than the average in our sample.

Column 6 reports the cross-country standard deviation of the intensive margin of adoption by technology while column 10 reports the inter-quartile range. ${ }^{25}$ The conclusions are robust to using any of these two measures of dispersion so, for brevity, we base our discussion on the cross-country standard deviation. The dispersion in the intensive adoption margin varies significantly by technology ranging from 0.33 (rail passenger) to 0.89 (blast oxygen steel). To have a benchmark, we report, in column $12,(1-\alpha)$ times the cross-country standard deviation in log per capita income in 2000 for the same sample of countries for which we have plausible and precise estimates of the adoption margins for each technology. ${ }^{26}$ The ratio of the standard deviation in the intensive margin to the standard deviation of per capita income

\footnotetext{
${ }^{24}$ Comin and Hobjin (2010) discuss several reasons for obtaining implausible estimates. The 10 year cut off point for plausible estimates is to allow for inference error. The cutoff we use in the standard error of the estimate of $T_{\tau}$ for it to be precise is $\sqrt{2003-\underline{v}_{\tau}}$. This allows for longer confidence intervals for older technologies with potentially more imprecise data. Including imprecise estimates in our analysis does not affect the conclusions.

${ }^{25}$ The inter-quartile range is defined as the difference between the adoption intensities in countries in the 75 and 25 percentiles.

${ }^{26}$ We scale down log income by the factor $(1-\alpha)$ because, in addition to the effect through TFP, the extensive margin also induces a higher capital-labor ratio which also affects the level of per capita output.
} 
is on average 1.2, but it ranges significantly across technologies: from 0.4 (for railways and electricity) ${ }^{27}$ to 1.72 for (blast oxygen steel). This suggests that technology-specific factors are important drivers of the cross-country variation in the intensive margin.

\section{Evolution}

The evolution of the intensive margin may be help us understand the dynamics of growth over the last two centuries. At first sight, the cross-country dispersion of the intensive margin seems to be uncorrelated with the invention date. We test this observation in the first column of Table 2, which reports the estimates from a regression of the average intensive margin, the cross-country dispersion and inter-quartile range on the year of invention. The regressions confirm an insignificant relationship between the dispersion of the intensive margin of adoption and the invention date of the technology.

One possible reason for the stationary nature of the dispersion of the intensive margin could be that our estimates of this dispersion for early adopters of early technologies are smaller than they should be because of the effect of the replacement of dominated technologies. The argument would be as follows. Some of the early technologies were dominated by superior technologies a long time ago. For early adopters such as the United States, the level of our measures for their intensive margin has been declining. As a result, the estimated intercept is lower than in late adopters, where these technologies have been dominated more recently. Under this hypothesis, cross-country dispersion in the intensive margin with which early technologies were adopted might have been larger than it now appears in the statistics. The alternative, of course, is that the stationarity of the cross-country dispersion in the intensive margin of adoption correctly represents the empirical facts.

To disentangle these two hypothesis, we re-estimate our baseline regression for the old technologies using only data up to 1939, when presumably none of the early technologies was yet obsolete. Table 3 compares the estimates of the average, standard deviation and inter-quartile range of the intensive margin of adoption for the countries for which we can precisely estimate the diffusion equation using data up to $1939 .^{28}$ The results vary a little by

\footnotetext{
${ }^{27}$ In particular, the ratio is 0.4 for passenger-Km moved by railways.

${ }^{28}$ For obvious reasons, we only report the estimates for technologies invented before 1900.
} 
technology but, overall, there are no significant increases in the dispersion of the intensive margin of adoption when we restrict the sample to the pre-1939 period. This implies that the dispersion in the intensive margin of adoption for early technologies is not driven by the fact that early technologies have been dominated sooner in countries that adopted them first.

The lack of convergence in the intensive margin contrasts with the evolution of the dispersion in adoption lags. Column 11 of Table 1 reports the cross-country standard deviation of the adoption lags for each technology. It is evident at first sight that dispersion in adoption lags has decreased monotonically over the last two centuries. That is, the difference in adoption lags across countries has been much smaller for technologies invented in the recent past than for those invented in the more distant past. Column 3 in Table 2 test this observation formally. The negative relationship between cross-country dispersion in adoption lags and invention date is statistically significant. In particular, technologies invented ten years later have a dispersion that is two years smaller.

\section{Variance decomposition}

Understanding the sources of variation in the intensive margin of adoption is beyond the scope of this paper. However, we can explore whether this variation is mostly driven by country effects or by technology effects. Specifically, let $\Delta_{j \tau}$ measure the intensive margin of country $j$ in technology $\tau$. We can decompose $\Delta_{j \tau}$ as follows

$$
\Delta_{j \tau}=\Delta_{j}+\Delta_{\tau}+u_{i \tau}
$$

where $\Delta_{j}$ is a country fixed effect, $\Delta_{\tau}$ is a technology fixed effect and $u_{i \tau}$ is an error term. The first line of Table 4 examines the contribution of the country fixed effects alone. That is, the $R^{2}$ when estimating (35) with only country fixed effects. Country-specific factors explain approximately $44 \%$ of the variation in the intensive margin of adoption. In the second row, we calculate the contribution of technology-specific fixed effects in an analogous manner and find that they explain $34 \%$ of the variation. The last row of Table 4 shows that country and technology specific factors jointly account for approximately $77 \%$ of the variation in the 
intensive margin. Of this total variation, $43 \%$ can be directly attributed to country effects, $33 \%$ can be directly attributed to technology effects, and the remaining $1 \%$ is due to the covariance between these effects which differs from zero because our panel is unbalanced.

The drivers of the variance in the intensive margin differ quite a bit from the drivers of the variance for the extensive. As shown in Comin and Hobijn (2010), the technology fixed effects account for $65 \%$ of the variance in the adoption lags. In contrast, country fixed effects are the main factor when accounting for the variance of the intensive margin of adoption.

\section{Non-homotheticities}

As discussed in the identification section, we want to explore an alternative approach to dealing with the endogeneity of income in estimating the intensive margin. So far we have used restrictions imposed by the assumption of balanced growth on the elasticity of our technology measures with respect to GDP (equation 30). We would like to explore how robust the estimates of the intensive margin are to using other identification schemes. In particular, the alternative scheme consists in identifying the effect of aggregate demand on technology by using the time series variation in GDP in the United States and then imposing the estimate of the U.S. income elasticity when estimating the reduced form equation (34) for the other countries.

As discussed above, when estimating the income elasticity for the United States, we want to distinguish between the short and long run income elasticities, since the former is likely to capture cyclical variation in the demand for investment goods. This presumption is confirmed by our estimates. We find that the long-run income elasticity is 2.2 , while the short-run is 6.6. Both estimates are very precise.

The additional flexibility allowed in the model comes at the cost of a lower precision in the estimates of the adoption lag for two U.S. technologies: ships and electricity. This creates the minor problem of having a less precise estimate for the United States in the intensive margin. Since we do not want to have as baseline intensity for the technology an imprecise estimate, for these two technologies, we take France as a reference rather than the United States. Which country is taken as baseline is irrelevant for computing the cross-country dispersion measures. However, the mean intensive margin of adoption may be affected; therefore, the 
average intensive margin is not directly comparable with the homothetic case.

We obtain plausible and precise estimates for 738 country-technology pairs. This represents $57 \%$ of our sample. The statistics for the estimated adoption lags and the intensive margin are reported in Table 5. On average, adoption lags are slightly smaller (35 years versus 45 years) when we allow for non-homotheticities. The cross-country dispersion in adoption lags is also slightly smaller (33 years versus 39 years) under non-homotheticities. However, the estimates of the adoption lags under both identification strategies are very highly correlated (see column 3 in Table 6). The average correlation across technologies is 0.91, and ranges from 0.79 for electricity to 0.98 for cellphones, MRIs and the Internet.

The cross-country dispersion in both measures of the intensive margin quite similar (0.72 versus 0.68). Column 4 in Table 6 shows the correlation between the estimates of the intensive margin of adoption in the homothetic and non-homothetic cases. On average the correlations are high, approximately 0.87. By technology, they range from 0.6 for freight railways to 0.97 for passenger aviation and cellphones.

\section{Correlation with per capita income}

Before using our model to conduct a development accounting exercise, it is revealing to explore the correlation between per capita income and the intensive margin of adoption for each technology. Table 7 reports these statistics for both the homothetic and non-homothetic estimates. The correlations are sizable. In the homothetic case the average correlation across technologies is $67 \%$ and in the non-homothetic case it is $64 \%$. We find some variation across technologies. The correlation of the intensive margin with per capita income seems to be lower for the earlier technologies, especially for ships and railways. Contrary to the perception that information technologies may be closing the technological divide between rich and poor countries, we find that the intensive margin of these technologies (i.e. PCs, cellphones, Internet) present quite high correlations with per capita income.

Table 7 also reports the correlation between the adoption lags and per capita income. As shown by Comin and Hobijn (2010) for the homothetic case, the correlation is also fairly high, approximately $-46 \%$. In the last column, we show that the there is also a significant correlation between the adoption lags in the non-homothetic case and per capita income 
though slightly lower than in the homothetic case $(-30 \%)$.

\subsection{Development accounting}

Next, we investigate how the estimated differences in the intensive margin of adoption translate into cross-country differences in per capita income. To answer this question, we have to (i) aggregate the technology-level estimates of the intensive margin to an economy-wide measure of the intensive margin, and (ii) compute the effect of the aggregate intensive margin on per capita income. Both of these computations require the use of a model that maps individual technologies into aggregate productivity. We naturally draw from the equilibrium relationships of the model presented above.

Aggregate production, $Y$, can be expressed as

$$
Y=A K^{\alpha} L^{1-\alpha}, \quad \text { where } K \equiv \int_{-\infty}^{t} K_{v} d v, L \equiv \int_{-\infty}^{t} L_{v} d v
$$

Aggregate TFP, $A$, is given by

$$
A=\left[\sum_{\tau \in\{o, n\}}\left(A_{\tau}\right)^{\frac{1}{\mu-1}}\right]^{\mu-1}=\left(\frac{\mu-1}{\gamma}\right)^{\mu-1} N^{\mu^{\prime}-1} Z_{\underline{v}} e^{\gamma(t-D-\underline{v})}
$$

Aggregate TFP depends on the adoption lag, $D$, the number of producers that adopter each technology vintage, $N$, and the normalized level of productivity, $Z_{\underline{v}}$. The adoption lag affects aggregate TFP because a higher $D$ reduces the productivity embodied in the best technology vintage available for production. The number of adopters per vintage, $N$, affects TFP because their outputs are imperfect substitutes and there are efficiency gains from a greater variety of outputs.

Substituting (37) into (36) and noting that $\phi_{R} K R=\alpha Y$ yields the following expression for labor productivity:

$$
\frac{Y}{L}=A^{\frac{1}{1-\alpha}}\left(\frac{K}{Y}\right)^{\frac{\alpha}{1-\alpha}}=\left[\left(\frac{\mu-1}{\gamma}\right)^{\mu-1} N^{\mu^{\prime}-1} Z_{\underline{v}} e^{\gamma(t-D-\underline{v})}\right]^{\frac{1}{1-\alpha}}\left(\frac{\alpha}{\phi_{R} R}\right)^{\frac{\alpha}{1-\alpha}}
$$


Taking logs, we obtain:

$$
y-l=\bar{c}+\frac{1}{1-\alpha}\left[\left(\mu^{\prime}-1\right) n+z_{\underline{v}}-\alpha\left(r+\ln \phi_{R}-\ln (\alpha)\right]+\frac{\gamma(t-D-\underline{v})}{1-\alpha}\right.
$$

where $\bar{c}$ is a constant. The term in squared brackets is equal to the economy-wide intensive margin of adoption. Subtracting the same expression for the U.S. yields

$$
\left(y_{j}-l_{j}\right)-\left(y_{U S}-l_{U S}\right)=\frac{1}{1-\alpha} \Delta_{j}-\frac{\gamma *\left(D_{U S}-D_{j}\right)}{1-\alpha}
$$

where $\left(\widehat{y_{j}-l_{j}}\right), \hat{D}_{j}$ and $\Delta_{j}$ denote, respectively, log-labor productivity, the adoption lag and the intensive margin in country $j$ relative to the U.S. ${ }^{29}$

Using expression (39), we can decompose the cross-country variance of labor productivity as

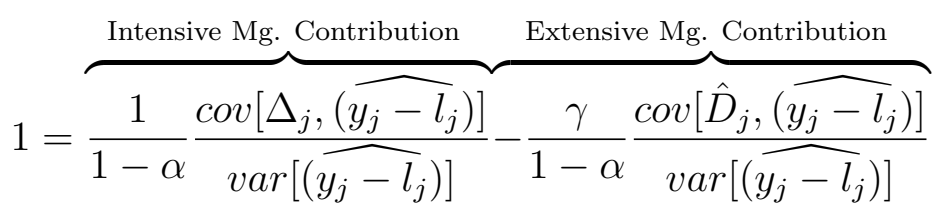

where $\operatorname{var}[X]$ denotes the variance of $X$, and $\operatorname{cov}[X, Y]$ denotes the covariance between $X$ and $Y$. The first term is the share of the cross-country variance in per-capita income accounted for the intensive margin, while the second term is the share of income differences accounted for the extensive margin. ${ }^{30}$ Under our model, together these two terms should account for $100 \%$ of the cross-country differences in productivity.

To implement the decomposition, we need to compute the aggregate intensive margin, $\Delta_{j}$. To this end, we assume that the intensive margins we have estimated using our sample of technologies are representative of the average intensive margin of adoption across all the technologies used in production. Under this assumption, the aggregate intensive margin in country $j$ is equal to the average intensive margin in the country across the technologies in

\footnotetext{
${ }^{29}$ Formally, $\left({\widehat{y_{j}-l_{j}}}_{j} \equiv\left(y_{j}-l_{j}\right)-\left(y_{U S}-l_{U S}\right)\right.$ and $\hat{D}_{j} \equiv\left(D_{j}-D_{U S}\right)$.

${ }^{30}$ This variance decomposition follows the decomposition in Klenow and Rodriguez-Clare (1997) and splits the co-variance between the intensive and extensive margins evenly between the two terms.
} 
our sample. ${ }^{31}$

Figure 2 plots the first term in equation (39) against log per capita income in 2000 from the Penn World Tables 6.2. ${ }^{32}$ The thicker dashed line corresponds to the regression line, while the light grey line is the $45^{\circ}$-line. The slope of the regression line is equal to the contribution of the intensive margin in (40). We find that the slope of the regression line is $0.44{ }^{33}$ This implies that the intensive margin of technology adoption accounts for $44 \%$ of the log per capita GDP differentials observed in the data.

Note that there is an heteroskedastic pattern, as poor countries have more variance in the measure of the intensive margin. This may be explained by the fact that we have fewer observations for poor countries than rich countries, and as a result, our measure of the average intensive margin is more noisy in poor countries.

Finally, we perform a development accounting exercise analogous to the one discussed above for the estimates obtained using a non-homothetic production function. The presence of non-homotheticities prevents the existence of a simple aggregate production function such as we have in our baseline model. To conduct this exercise, we assume, as a first pass, that the aggregate production function does not differ much from the one obtained in the homothetic case. Since our goal is to evaluate the robustness of our findings to alternative identification schemes in the estimation of the intensive margin of technology, it is desirable to use the same production function to draw the aggregate implications of the technology-specific estimates. It turns out that the development accounting exercise for the non-homothetic estimates of the intensive margin yields very similar results to the baseline exercise, as it can be seen in Figure 3 The correlation between the intensive margin and income per capita is 0.67 , and the coefficient on the regression is 0.52 .

To sum up, this section suggests that differences in the intensive margin of adoption account for over $40 \%$ of cross-country per capita income differences. The observation that a

${ }^{31}$ Formally,

$$
\Delta_{j} \simeq \frac{\sum_{s=1}^{S_{j}} \Delta_{j s}}{S_{j}}
$$

where $S_{j}$ is the total number of technologies for which we have precise and plausible estimates in country $j$.

${ }^{32}$ Similar results obtain with data from Maddison.

${ }^{33}$ The correlation between the two sides is 0.51 . 
substantial share of income differences are either caused or amplified by the intensive margin of adoption is robust to the two identification strategies we have followed to deal with the endogeneity of aggregate demand to technology.

\section{Conclusion}

In this paper we have built and estimated a model of technology diffusion and growth. Our model predicts that the diffusion path of individual technologies is determined by the lag with which their different vintages are introduced in the country, the level of aggregate demand and the intensive margin of adoption. Using these predictions and exploiting the panel structure of our data set, we have identified the intensive and extensive margins of adoption for over 800 technology-country pairs that correspond to the diffusion of up to 15 major technologies in 166 countries. The estimates are robust to different strategies used to estimate the elasticity of technology with respect to aggregate demand.

An analysis of the estimates yields significant findings. There is a large cross-country dispersion in the intensive margin, though the dispersion varies significantly across technologies. The cross-country dispersion in adoption lags has declined very significantly over the last two centuries, while we find no such convergence pattern in the intensive margin.

In addition to describing accurately the diffusion patterns of individual technologies, our model yields a representation of aggregate productivity that allows us to relate income levels to the intensive and extensive margins of technology adoption. We find that approximately $45 \%$ of the cross-country variation in per capita income can be attributed to differences in the intensive margin. Comin and Hobijn (2010) reported that differences in the extensive margin account for at least $25 \%$ percent of the cross country variation in productivity. Taken together, these results imply that the role of technology is crucial to understanding per capita income differences. In particular, the empirical estimates suggest that $70 \%$ of the differences in cross-country income per capita can be explained by differences in technology adoption.

We anticipate that the findings of this paper will stimulate three lines of research. First, we would like to understand better the relative importance of the different drivers of the intensive margin. In particular, we would like to assess what is the role played by adoption 
costs, institutional constraints that affect the overall efficiency of the economy and distortions that affect the price of capital. Second, we plan to study the underpinnings of the variation in adoption costs which this paper abstracts from. Specifically, our findings beg the question of why adoption costs at both the extensive and intensive margin are so large in developing countries. Finally, the differences we have observed in both the intensive and extensive margins across technologies suggest that maybe the dynamics of technology adoption are important not only to understanding cross-country differences in productivity but to explaining the dynamics of growth over the last two centuries. In particular, we intend to explore whether the dynamics of adoption uncovered in this paper can explain the Great Divergence and the lack of absolute convergence over the post-war period. 


\section{References}

[1] Basu, Susanto, and John G. Fernald. 1997. "Returns to Scale in U.S. Production: Estimates and Implications." Journal of Political Economy, 105(2): 249-283.

[2] Basu, Susanto, and David N. Weil. 1998. "Appropriate Technology and Growth." Quarterly Journal of Economics, 113(4): 1025-1054.

[3] Caselli, Francesco, and W. John Coleman. 2001. "Cross-Country Technology Diffusion: The Case of Computers." American Economic Review - AEA Papers and Proceedings, 91(2): 328-335.

[4] Clark, Gregory. 1987. "Why Isn't the Whole World Developed? Lessons from the Cotton Mills." Journal of Economic History, 47(1): 141-173.

[5] Comin, Diego, and Mark Gertler. 2006. "Medium Term Business Cycles." The American Economic Review, (96)3: 523-551.

[6] Comin, Diego, and Bart Hobijn. 2004. "Cross-Country Technology Adoption: Making the Theories Face the Facts." Journal of Monetary Economics, 51(1): 39-83.

[7] Comin, Diego, and Bart Hobijn. 2008. "An Exploration of Technology Diffusion." HBS working paper 08-093.

[8] Comin, Diego, and Bart Hobijn. 2010. "An Exploration of Technology Diffusion." The American Economic Review, forthcoming.

[9] Comin, Diego, Bart Hobijn, and Emilie Rovito. 2006. "Five Facts You Need to Know About Technology Diffusion." NBER Working Paper \#11928.

[10] Comin, Diego, Bart Hobijn, and Emilie Rovito. 2008. "A New Approach to Measuring Technology with an Application to the Shape of the Diffusion Curves." Journal of Technology Transfer, 33(2): 187-207.

[11] Gollin, Douglas. 2002. "Getting Income Shares Right." Journal of Political Economy, 110(2): 458-474. 
[12] Gort, Michael, and Steven Klepper. 1982. "Time Paths in the Diffusion of Product Innovations." Economic Journal, 92: 630-653.

[13] Griliches, Zvi. 1957. "Hybrid Corn: An Exploration in the Economics of Technological Change." Econometrica, 25(4): 501-522.

[14] Hall, Robert E., and Charles I. Jones. 1999. "Why Do Some Countries Produce So Much More Output per Worker than Others?" Quarterly Journal of Economics, 114(1): 83-116.

[15] Hsieh, Chang-Tai. 2002. "What Explains the Industrial Revolution in East Asia? Evidence from the Factor Markets." American Economic Review, 92(3): 502-526.

[16] Jerzmanowski, Michael. 2007. "Total Factor Productivity Differences: Appropriate Technology vs. Efficiency.", European Economic Review, 51(8): 2080-2110.

[17] Klenow, Peter J., and Andrés Rodríguez-Clare. 1997. "The Neoclassical Revival in Growth Economics: Has It Gone Too Far?" NBER Macroeconomics Annual, 12: 73-103.

[18] Maddison, Angus. 2007. Contours of the World Economy 1-2030 AD: Essays in Macro-Economic History. Oxford: Oxford University Press.

[19] Mansfield, Edwin. 1961. "Technical Change and the Rate of Imitation." Econometrica, 29(4): 741-766.

[20] Manuelli, Rodolfo, and Ananth Sheshadri. 2003. "Frictionless Technology Diffusion: The Case of Tractors." NBER Working Paper \# 9604.

[21] Parente, Stephen L., and Edward C. Prescott. 1994. "Barriers to Technology Adoption and Development." Journal of Political Economy, 102(2): 298-321.

[22] Saxonhouse, Gary R., and Gavin Wright. 2004. "Technological Evolution in Cotton Spinning, 1878-1933." in The Fibre that Changed the World, eds. Douglas A. Farnie and David J. Jeremy. Oxford: Oxford University Press. 
[23] Young, Alwyn. 1992. "A Tale of Two Cities: Factor Accumulation and Technical Change in Hong Kong and Singapore." NBER Macroeconomics Annual, 7: 13-54.

[24] Young, Alwyn. 1995. "The Tyranny of Numbers: Confronting the Statistical Realities of the East Asian Growth Experience." Quarterly Journal of Economics, 110(3): 641680.

\section{A Data}

The data that we use are taken from two sources. Real GDP and population data are taken from Maddison (2007). The data on the technology measure are from the Cross-Country Historical Adoption of Technology (CHAT) data set, first described in Comin, Hobijn, and Rovito (2006). The fifteen particular technology measures, organized by broad category, that we consider are:

1. Steam and motor ships: Gross tonnage (above a minimum weight) of steam and motor ships in use at midyear. Invention year: 1788; the year the first (U.S.) patent was issued for a steam boat design.

2. Railways - Passengers: Passenger journeys by railway in passenger-KM. Invention year: 1825; the year of the first regularly schedule railroad service to carry both goods and passengers.

3. Railways - Freight: Metric tons of freight carried on railways (excluding livestock and passenger baggage). Invention year: 1825; same as passenger railways.

4. Telegraph: Number of telegrams sent. Invention year: 1835; year of invention of telegraph by Samuel Morse at New York University.

5. Telephone: Number of mainline telephone lines connecting a customer's equipment to the public switched telephone network as of year end. Invention year: 1876; year of invention of telephone by Alexander Graham Bell. 
6. Electricity: Gross output of electric energy (inclusive of electricity consumed in power stations) in KwHr. Invention year: 1882; first commercial power-station on Pearl Street in New York City.

7. Cars: Number of passenger cars (excluding tractors and similar vehicles) in use. Invention year: 1885; the year Gottlieb Daimler built the first vehicle powered by an internal combustion engine.

8. Trucks: Number of commercial vehicles, typically including buses and taxis (excluding tractors and similar vehicles), in use. Invention year: 1885; same as cars.

9. Aviation - Passengers: Civil aviation passenger-KM traveled on scheduled services by companies registered in the country concerned. Invention year: 1903; The year the Wright brothers managed the first successful flight.

10. Aviation - Freight: Civil aviation ton-KM of cargo carried on scheduled services by companies registered in the country concerned. Invention year: 1903; same as aviation - passengers.

11. Blast Oxygen Steel: Crude steel production (in metric tons) in blast oxygen furnaces (a process that replaced Bessemer and OHF processes). Invention year: 1950; invention of Blast Oxygen Furnace.

12. Cellphones: Number of users of portable cell phones. Invention year: 1973; first call from a portable cellphone.

13. Personal computers: Number of self-contained computers designed for use by one person. Invention year: 1973; first computer based on a microprocessor.

14. MRIs: Number of magnetic resonance imaging (MRI) units in place. Invention year: 1977; first MRI-scanner built.

15. Internet users: Number of people with access to the worldwide network. Invention year: 1983; introduction of TCP/IP protocol. 


\section{B Equilibrium and diffusion of the new technology}

Let $\Gamma_{t}$ denote the total adoption costs at instant $t$. Then

$$
\begin{aligned}
\Gamma_{t} & =\bar{\Psi}\left(1+b_{e}\right)\left(\frac{\gamma}{\mu-1}\right) e^{-\frac{\vartheta}{\mu-1} \gamma D}\left(\frac{Z_{0} e^{\gamma \bar{v}}}{A_{t}}\right)^{\frac{1}{\mu-1}} Y_{t}(1-\dot{D}) \\
& +\bar{\Psi}\left(1+b_{i}\right)\left(Z_{0} A_{t} e^{\gamma t}\right)^{-\frac{1}{\mu-1}} Y_{t} \int_{-\infty}^{v_{t}} Z_{v}^{\frac{1}{\mu-1}} \dot{N}_{v}(t) d v .
\end{aligned}
$$

where $\dot{D}$ denotes the time derivative of the adoption lags. Note that along the Balance Growth Path, the distribution over the vintages for which the measure of varieties adopted becomes degenerate around $\bar{v}_{t}$ and the aggregate costs become $\Gamma_{v t}^{i} N_{v}$.

The equilibrium path of the aggregate resource allocation in this economy can be defined in terms of the following nine equilibrium variables $\{C, K, I, \Gamma, Y, A, N, D, V\}$. Just like in the standard neoclassical growth model, the capital stock, $K$, is the only state variable. The eight equations that determine the equilibrium dynamics of this economy are given by

(i) The consumption Euler equation.

(ii) The aggregate resource constraint ${ }^{34}$

$$
Y=C+I+\Gamma
$$

(iii) The capital accumulation equation

$$
\dot{K}=-\delta K+I
$$

(iv) The production function, (11), taking into account that in equilibrium $L=1$.

(v) The adoption cost functions (6) and (7).

(vi) The technology adoption equations, which determine the adoption lag (20) and the intensive margin of adoption (16).

\footnotetext{
${ }^{34} \mathrm{We}$ assume that adoption costs are measured as part of final demand, such that $Y$ can be interpreted as GDP.
} 
(vi) The stock market to GDP ratio, (14). ${ }^{35}$

(vii) The aggregate TFP level, 12.

\footnotetext{
${ }^{35}$ The dynamics of $\Psi_{t}^{e}$ and $\Psi_{t}^{i}$ are what are considered in the system of equilibrium equations. For example, the law of motion of for $\Psi_{t}^{e}$ is (omitting superscripts and subscripts) $\frac{\dot{\Psi}}{\Psi}=\left\{\alpha \frac{\epsilon-1}{\epsilon} \frac{Y}{K}-\delta+\frac{1}{\mu-1} \frac{\dot{A}}{A}-\frac{\dot{Y}}{Y}\right\}-\frac{\alpha}{\epsilon} \frac{1}{\Psi}$.
} 


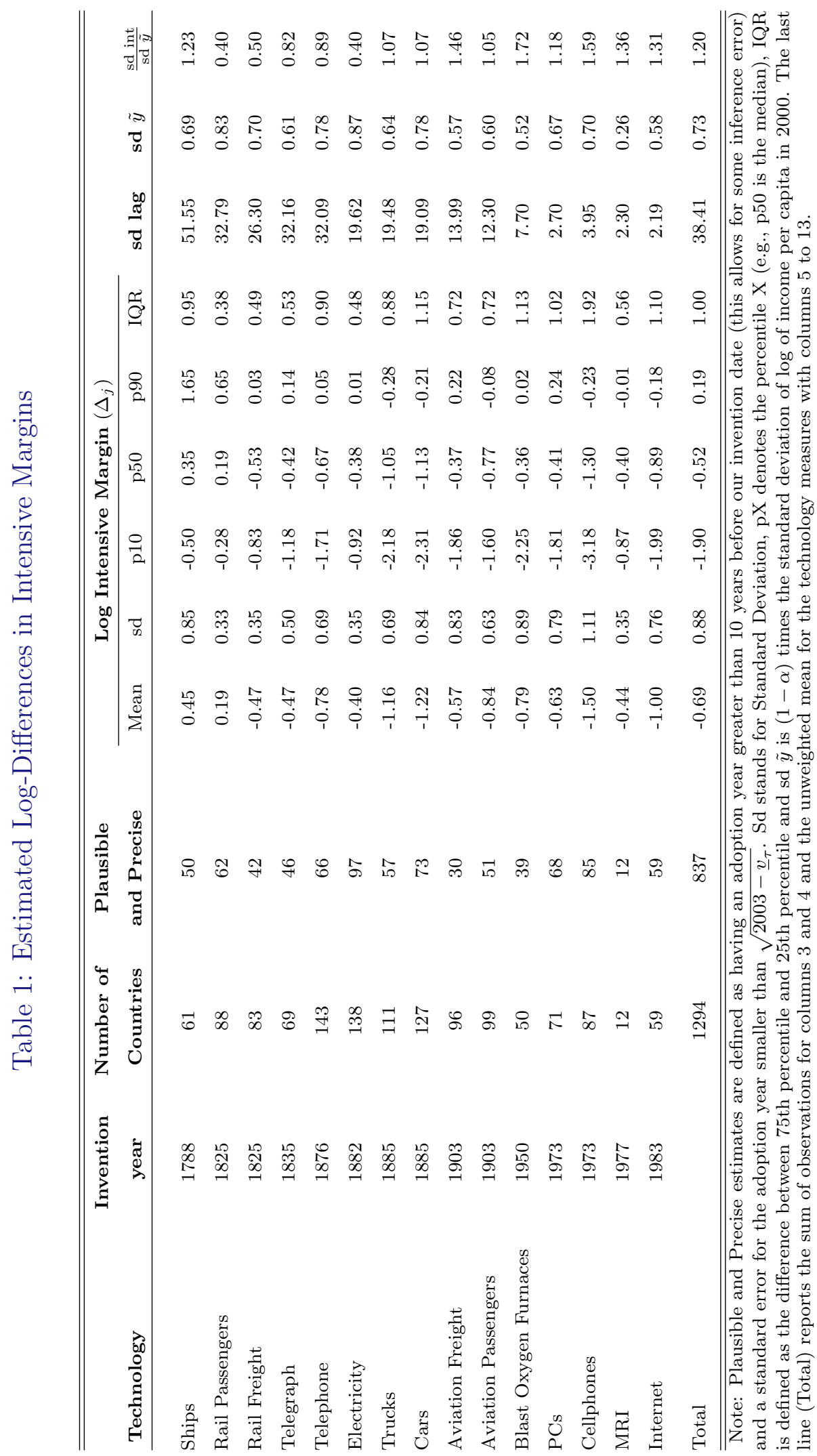


Table 2: Evolution of the Distribution of the Intensive and Extensive Margin

\begin{tabular}{|c|c|c|c|c|}
\hline & \multicolumn{2}{|c|}{ 100*Log-Intensive Margin } & \multicolumn{2}{|c|}{ Adoption Lag } \\
\hline & Homothetic & Non-Homothetic & Homothetic & Non-Homothetic \\
\hline \multirow[t]{2}{*}{ Mean } & -0.50 & -0.21 & -.50 & -.40 \\
\hline & $(0.19)$ & $(0.10)$ & $(.06)$ & $(.06)$ \\
\hline \multirow[t]{2}{*}{ Std.Dev. } & 0.14 & -0.04 & -.22 & -.23 \\
\hline & $(0.12)$ & $(0.07)$ & $(.02)$ & $(.04)$ \\
\hline \multirow[t]{2}{*}{ IQR } & 0.32 & 0.01 & -.39 & -.40 \\
\hline & $(0.18)$ & $(0.11)$ & $(.09)$ & $(.09)$ \\
\hline
\end{tabular}

Note: Robust standard errors are shown in parenthesis. Mean refers to the average of the intensive or extensive margin. The Homothetic column refers to the baseline model, while the Non-homothetic refers to the estimation with a non-homothetic production function. Std. Dev. refers to the Standard Deviation and IQR, to the Interquartile Range (difference between the 75th and 25th percentiles). All these technology measures are regressed on the year of invention of the technology.

Table 3: Comparison of Intensive Margin Estimates up to 1939 versus Whole Sample

\begin{tabular}{lcccccccc}
\hline \hline & $\begin{array}{c}\text { Adoption } \\
\text { Technology }\end{array}$ & $\begin{array}{c}\text { Number of } \\
\text { Countries }\end{array}$ & $\begin{array}{c}\text { Mean } \\
\mathbf{1 9 3 9}\end{array}$ & Mean & $\begin{array}{c}\text { Std.Dev. } \\
\mathbf{1 9 3 9}\end{array}$ & Std.Dev. & IQR & IQR \\
\hline Ships & 1788 & 12 & 0.06 & -0.11 & 0.38 & 0.63 & 0.39 & 0.67 \\
Rail Freight & 1825 & 12 & -0.49 & -0.57 & 0.25 & 0.31 & 0.32 & 0.45 \\
Rail Passengers & 1825 & 17 & 0.14 & 0.24 & 0.16 & 0.19 & 0.17 & 0.23 \\
Telegraph & 1835 & 20 & -0.13 & -0.54 & 0.29 & 0.54 & 0.37 & 0.62 \\
Telephone & 1876 & 9 & -0.38 & -0.35 & 0.28 & 0.28 & 0.31 & 0.35 \\
Electricity & 1882 & 18 & -0.24 & -0.20 & 0.23 & 0.18 & 0.38 & 0.26 \\
Cars & 1885 & 11 & -0.99 & -0.75 & 0.56 & 0.48 & 0.63 & 0.60 \\
Trucks & 1885 & 10 & -0.96 & -1.01 & 0.63 & 0.73 & 1.00 & 1.02 \\
Total & & & -0.31 & -0.37 & 0.51 & 0.56 & 0.59 & 0.69 \\
\hline \hline
\end{tabular}

Note: Number of countries is the number of countries for which we have plausible and precise estimates using data up to 1939. Mean 1939 refers to the mean intensive margin of a technology obtained using data up to 1939. Mean refers to the mean intensive margin of a technology obtained using data for the whole sample (up to 2003). An analogous notation is used for the standard deviation (Std. Dev.) and the interquartile range (IQR). 
Table 4: Analysis of variance

\begin{tabular}{lc|ccc|c}
\hline \hline & $\begin{array}{c}\text { Model } \\
\text { SS }\end{array}$ & $\begin{array}{c}\text { Country } \\
\text { effect }\end{array}$ & $\begin{array}{c}\text { Technology } \\
\text { effect }\end{array}$ & $\begin{array}{c}\text { Residual } \\
\text { SS }\end{array}$ & $\begin{array}{c}\text { Total } \\
\text { SS }\end{array}$ \\
\hline Country effect alone & $44 \%$ & $44 \%$ & & $56 \%$ & $100 \%$ \\
Technology effect & $34 \%$ & & $34 \%$ & $66 \%$ & $100 \%$ \\
Joint effect & $77 \%$ & $43 \%$ & $33 \%$ & $23 \%$ & $100 \%$ \\
\hline \hline
\end{tabular}

Note: Decomposition of the intensive margin estimates. The percentages are obtained from the ratio of the sum of squares of the country or technology dummy over the total.

Table 5: Estimates of Adoption Lags and Intensive Margin allowing for non-homotheticities

\begin{tabular}{|c|c|c|c|c|c|c|c|}
\hline \multirow[b]{2}{*}{ Technology } & \multirow{2}{*}{$\begin{array}{c}\text { Invention } \\
\text { year }\end{array}$} & \multirow{2}{*}{$\begin{array}{c}\text { Number } \\
\text { of Countries }\end{array}$} & \multirow{2}{*}{$\begin{array}{c}\text { Plausible } \\
\text { and Precise }\end{array}$} & \multicolumn{2}{|c|}{ Adoption Lags } & \multicolumn{2}{|c|}{ Log-Int. Margin } \\
\hline & & & & Mean & $\mathrm{sd}$ & Mean & $\mathrm{sd}$ \\
\hline Ships & 1788 & 61 & 31 & 101.61 & 59.72 & 0.5 & 0.82 \\
\hline Railways freight & 1825 & 88 & 58 & 82.28 & 26.30 & 0.38 & 0.41 \\
\hline Rail passengers & 1825 & 83 & 40 & 61.78 & 31.51 & 0.09 & 0.43 \\
\hline Telegraph & 1835 & 69 & 37 & 38.39 & 32.03 & 0.02 & 0.59 \\
\hline Telephone & 1876 & 143 & 64 & 44.73 & 31.37 & 0.15 & 0.62 \\
\hline Electricity & 1882 & 138 & 50 & 34.42 & 25.60 & -0.03 & 0.63 \\
\hline Trucks & 1885 & 111 & 53 & 32.97 & 19.53 & -0.23 & 0.57 \\
\hline Cars & 1885 & 127 & 70 & 36.05 & 22.05 & -0.25 & 0.7 \\
\hline Aviation freight & 1903 & 96 & 36 & 37.58 & 14.89 & -0.03 & 0.72 \\
\hline Aviation passengers & 1903 & 99 & 53 & 27.98 & 13.95 & -0.42 & 0.76 \\
\hline Blast Oxygen Furnaces & 1950 & 50 & 41 & 15.63 & 6.68 & 0.03 & 0.5 \\
\hline $\mathrm{PCs}$ & 1973 & 71 & 62 & 13.96 & 2.86 & 0.17 & 0.54 \\
\hline Cellphones & 1973 & 87 & 75 & 13.44 & 3.85 & -0.44 & 0.76 \\
\hline MRIs & 1977 & 12 & 12 & 3.02 & 2.38 & -0.01 & 0.34 \\
\hline Internet & 1983 & 59 & 56 & 7.39 & 2.09 & -0.06 & 0.47 \\
\hline Total & & 1294 & 738 & 35.87 & 33.53 & -0.04 & 0.66 \\
\hline
\end{tabular}

Note: Plausible and Precise estimates are defined as having an adoption year greater than 10 years before our invention date (this allows for some inference error) and a standard error for the adoption year smaller than $\sqrt{2003-\underline{v}_{\tau}}$. Sd stands for Standard Deviation. The last line (Total) reports the sum of observations for columns 3 and 4 and the unweighted mean of technology measures for columns 5 to 8 . 
Table 6: Correlation by Technology of Homothetic and Non-Homothetic Margins

\begin{tabular}{lccc}
\hline \hline Technology & Observations & $\begin{array}{c}\text { Correlation } \\
\text { Intensive }\end{array}$ & $\begin{array}{c}\text { Correlation } \\
\text { Extensive }\end{array}$ \\
\hline Ships & 30 & 0.88 & 0.96 \\
Rail Passengers & 55 & 0.82 & 0.93 \\
Rail Freight & 38 & 0.60 & 0.85 \\
Telegraph & 34 & 0.92 & 0.91 \\
Telephone & 59 & 0.89 & 0.96 \\
Electricity & 45 & 0.84 & 0.79 \\
Trucks & 51 & 0.86 & 0.88 \\
Cars & 63 & 0.89 & 0.86 \\
Aviation Freight & 29 & 0.95 & 0.96 \\
Aviation Passengers & 51 & 0.97 & 0.90 \\
Blast Oxygen Furnaces & 38 & 0.93 & 0.96 \\
PCs & 60 & 0.84 & 0.82 \\
Cellphones & 75 & 0.97 & 0.98 \\
MRI & 12 & 0.80 & 0.98 \\
Internet & 56 & 0.90 & 0.98 \\
Total & 696 & 0.87 & 0.91 \\
\hline \hline
\end{tabular}

Note: The last line (Total) reports the total sum of observations in the second column and the unweighted average of technology correlations for columns 3 and 4 .

Table 7: Correlation of Intensive and Extensive Margin with log income per capita in 2000

\begin{tabular}{|c|c|c|c|c|c|c|c|}
\hline \multirow[b]{2}{*}{ Technology } & \multirow{2}{*}{$\begin{array}{c}\text { Invention } \\
\text { year }\end{array}$} & \multicolumn{3}{|c|}{ Homothetic } & \multicolumn{3}{|c|}{ Non Homothetic } \\
\hline & & Obs. & Int. Margin & Adoption Lag & Obs. & Int. Margin & Adoption Lag \\
\hline Ships & 1788 & 50 & 0.38 & -0.48 & 31 & 0.52 & -0.47 \\
\hline Rail Passengers & 1825 & 62 & 0.38 & -0.62 & 58 & 0.33 & -0.49 \\
\hline Rail Freight & 1825 & 42 & 0.16 & -0.67 & 40 & 0.46 & -0.30 \\
\hline Telegraph & 1835 & 46 & 0.46 & -0.49 & 37 & 0.49 & -0.28 \\
\hline Telephone & 1876 & 66 & 0.79 & -0.49 & 64 & 0.53 & -0.37 \\
\hline Electricity & 1882 & 97 & 0.76 & -0.57 & 50 & 0.68 & -0.27 \\
\hline Trucks & 1885 & 57 & 0.53 & -0.35 & 53 & 0.49 & -0.20 \\
\hline Cars & 1885 & 73 & 0.51 & -0.31 & 70 & 0.63 & 0.01 \\
\hline Aviation Freight & 1903 & 30 & 0.85 & -0.09 & 36 & 0.78 & 0.20 \\
\hline Aviation Passengers & 1903 & 51 & 0.80 & -0.13 & 53 & 0.79 & 0.23 \\
\hline Blast Oxygen Furnaces & 1950 & 39 & 0.90 & -0.33 & 41 & 0.80 & -0.35 \\
\hline $\mathrm{PCs}$ & 1973 & 68 & 0.69 & -0.31 & 62 & 0.66 & -0.40 \\
\hline Cellphones & 1973 & 85 & 0.92 & -0.57 & 75 & 0.88 & -0.51 \\
\hline MRI & 1977 & 12 & 0.79 & -0.39 & 12 & 0.61 & -0.44 \\
\hline Internet & 1983 & 59 & 0.95 & -0.75 & 56 & 0.84 & -0.82 \\
\hline Total & & 837 & 0.67 & -0.46 & 738 & 0.64 & -0.30 \\
\hline
\end{tabular}

Note: The Homothetic columns refer to the baseline model, while the Non-homothetic refer to the estimation using a nonhomothetic production function. The last line (Total) reports the total sum of observations in the third and sixth columns and the unweighted average of the correlations for columns 4, 5, 7 and 8. 


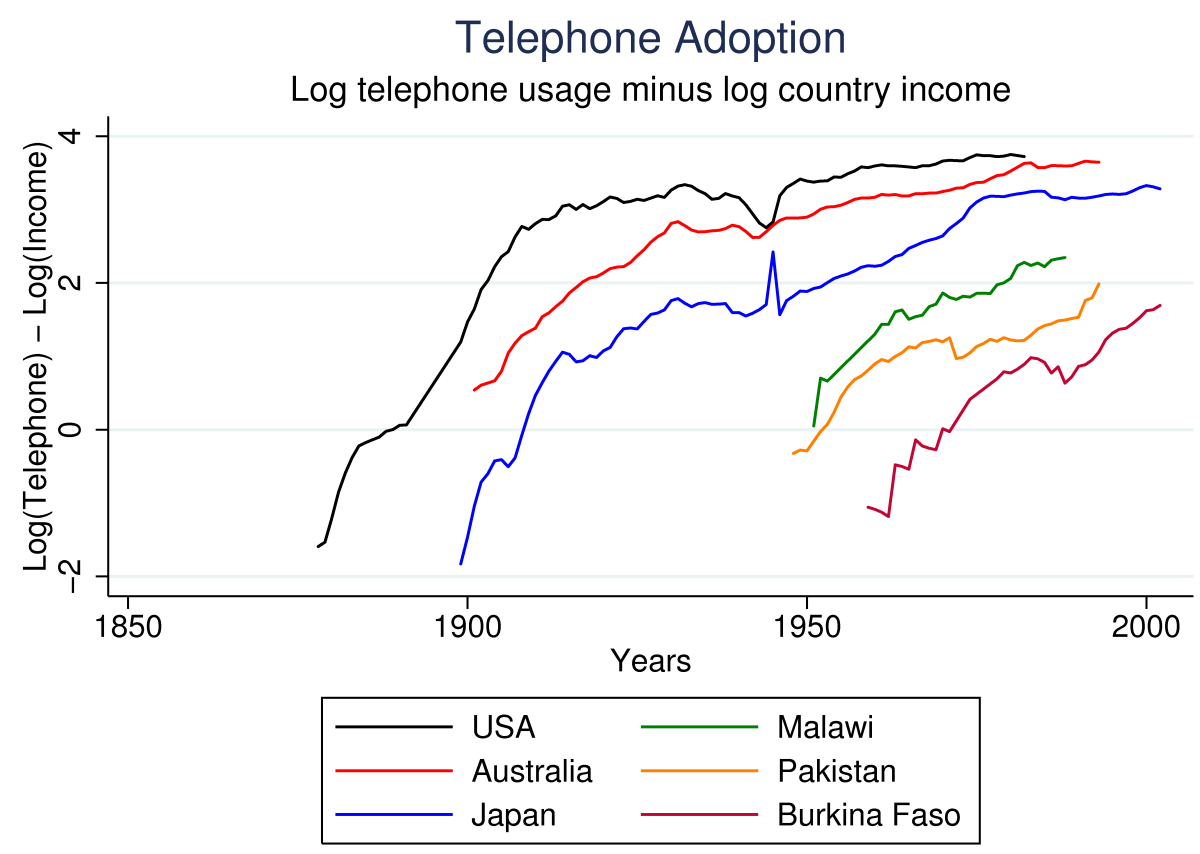

Figure 1: Differences in telephone adoption subtracting own country income for four different countries.

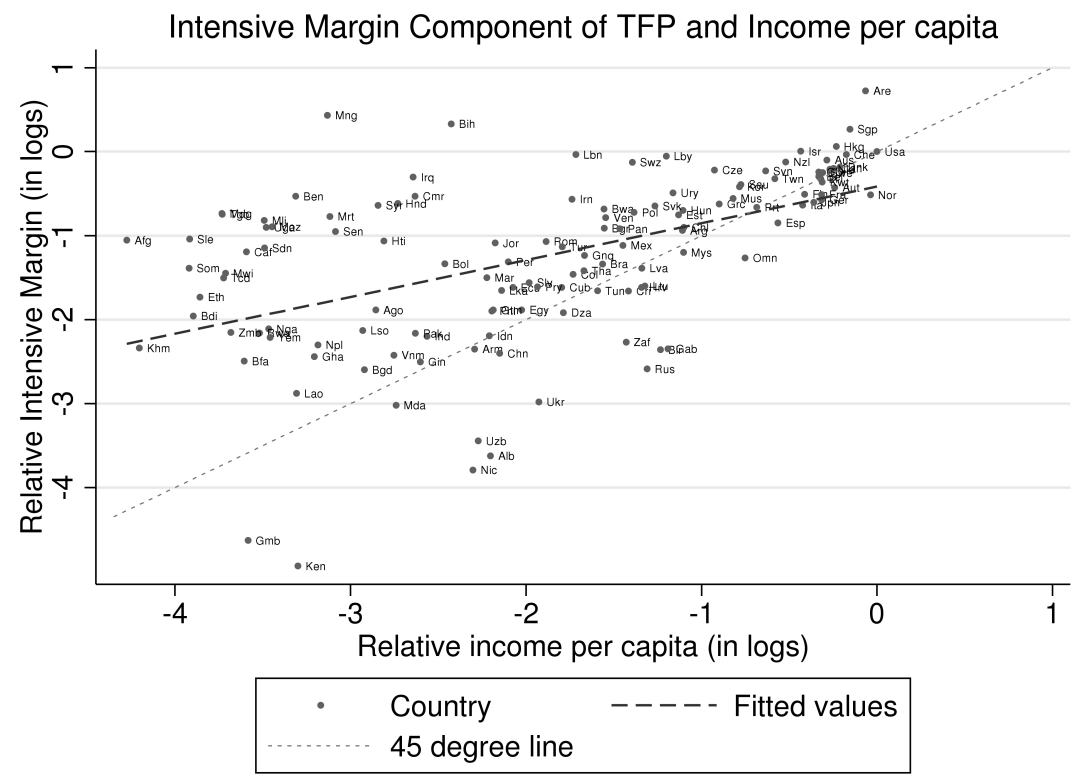

Figure 2: Intensive Margin component of TFP and differences in income per capita. The slope of the dashed line is .44. 


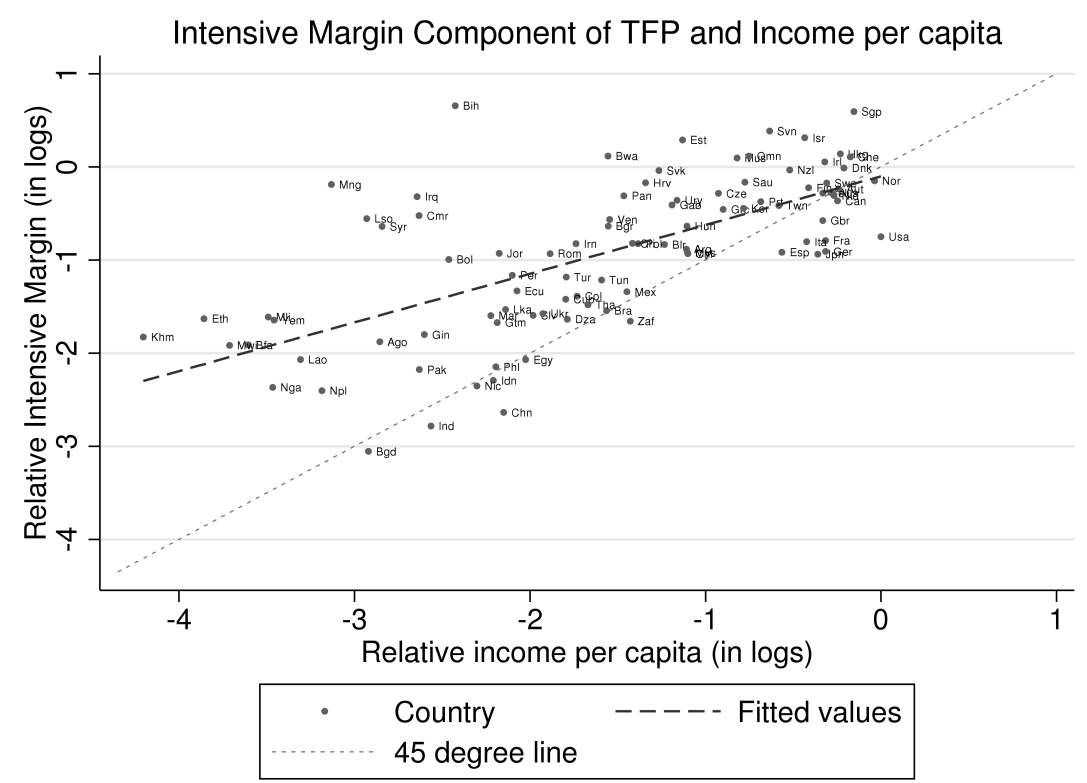

Figure 3: Intensive Margin component of TFP and differences in income per capita with non homotheticities. The slope of the dashed line is .52. 